\title{
Selection of Models: Evolution and the Choice of Species for Translational Research
}

\author{
Jessica A. Bolker \\ Department of Biological Sciences, University of New Hampshire, Durham, NH, USA
}

\section{Keywords}

Animal model · Evolution · Model organism · Translational research

\begin{abstract}
Evolutionary thinking can inform the choice and assessment of model species in neuroscience, particularly when such models are intended to generate knowledge that will translate to humans. Avoiding errors that arise from oversimplified notions of phylogeny or genotype-phenotype mapping is one contribution; evolutionary biology also offers positive guidance. The challenge of finding adequate non-human models for translational research is particularly acute in neuroscience: neurobiological and behavioral phenotypes are complex and plastic, and many traits important in humans are absent, radically different, or difficult to assess in other species. Evolutionary perspectives help to articulate and address these challenges. Darwin's description of "descent with modification" points to two aspects of evolution that can help us assess the matching between a prospective model species and its intended target. One is trees that represent the structure of phylogenetic relationships; the other is phenotypic traits, i.e. the unique characteristics of each species' evolved biology and natural history. Mapping traits onto a phylogeny is the first step toward analyzing the source of similarities between a target and a potential mod-
\end{abstract}

el. Whether similar traits arise from shared ancestry or from adaptive convergence has important implications for what kinds of inferences can be justified, and for the likely translatability of findings. Evolution offers both a rich source of possible models, and guidance for choosing the best ones for a given purpose. Considering model choice from an evolutionary angle not only helps to answer the question "What species might be a good model for studying $x$ ?" but also suggests additional questions we should be asking to assess the utility of both potential and current models. Recognizing the diverse ways model organisms can function expands our search image as we seek species to study that can both extend general knowledge, and generate translatable insights relevant to human neurobiology and disease.

(c) 2019 S. Karger AG, Basel

\section{Introduction}

"Selection" of models has two meanings: the term can refer to the human choice of species to use as models, or to the evolutionary reshaping of model species' traits in the laboratory environment. Evolutionary perspectives can help us better understand both processes, and guide the choice of model species for neuroscience research particularly research that is intended to translate into clinical benefits for humans.

\section{KARGER}

(c) 2019 S. Karger AG, Basel

E-Mail karger@karger.com

www.karger.com/bbe
Jessica A. Bolker

Department of Biological Sciences, University of New Hampshire 46 College Road

Durham, NH 03824 (USA)

E-Mail jbolker@unh.edu 
The challenge of finding adequate non-human models is particularly acute in neuroscience for many reasons. Key traits can be especially difficult to compare between species. Behavioral and neural networks may be inherently harder to assess than, say, morphology or gene expression. Neurobiological traits are often highly plastic, and thus influenced by environment and context to a greater degree than other aspects of the phenotype. Finally, humans are biological and behavioral outliers in many respects - perhaps especially with respect to our neurobiology [Matthews et al., 2005; Kaffman and Krystal, 2012; Horwitz et al., 2014; Puzzo et al., 2014; Kelava and Lancaster, 2016; Li et al., 2018; Boldog et al., 2018].

Choosing model organisms demands that we balance many considerations, including tractability and cost, how well the model represents its target, and the likelihood that findings in the model will translate into general understanding and/or clinical applications. Models can be used to gain translatable knowledge in two different ways: they may function as exemplars, whose role is primarily to enhance knowledge of basic biology, or serve as direct surrogates for a target species of interest [Bolker, 2009]. Exemplary models represent a broader taxon, work via inference, and are most commonly used for basic research. In contrast, surrogate models represent another particular species or group (e.g., patients with a specific disease), work via substitution, and are generally employed for clinical and applied work, including assessing the safety and efficacy of potential therapies. Many models function in both ways; which role they play depends on the research agenda, strategy, and context [Bolker, 2009, 2014].

Both forms of modeling are based on biological similarities that enable one species to effectively represent something about another, such as its physiology, neurobiology, or response to an experimental variable. Assessing relevant similarities a priori presents an epistemological challenge: in order to do so, we need to know the biology both of the target, and of the prospective model - especially aspects that are important to the phenomenon being studied. But the point of model-based research is to better understand precisely those aspects of the target's biology: if we already had such knowledge about the target, we would not need a model to study it. This conundrum is described by Steel [2008] as the "extrapolator's circle": the less we currently know about the target, the harder it is to judge what is essential for a model to represent, i.e., in what ways it needs to be similar. Hopeful assumptions are a tempting, but not a reliable, substitute [Striedter, 2019].

Selection of Models for Translational Research
One possible approach to evaluating and predicting similarity is to examine the problem from an evolutionary perspective. But we need to proceed with caution, and refrain from invoking evolution to support implicit - but unjustified - assumptions. For instance, arguments in favor of some neuroscience models claim evolutionary relevance based on diagrams that more closely resemble Aristotle's scala naturae, than a modern understanding of phylogenetic relationships [Preuss, 2000]. Nor should we elide ontogeny: another misleading shortcut is to treat the relationship between genotype and phenotype as a linear connection. While genes are central determinants of many traits, they are not the whole story. Because evolution and ecology also help shape traits (both in lineages and in individuals), we can gain insights from evo-devo about the importance of the ontogenetic "black box," and lessons from eco-devo about the role of the environment in shaping individual phenotypes [Bolker, 2003; Amundson, 2005; Gilbert and Epel, 2015].

However, evolutionary biology can do more for the modeling enterprise than just help avoid pitfalls: it offers positive guidance for selecting models and interpreting what they teach us, both in general and in the specific context of translational research [Springer and Murphy, 2007; Nesse et al., 2010; Perlman, 2016; Nesse, 2019]. Besides helping to avert translational failures by predicting where disparities between models and patients are especially likely, evolutionary knowledge can also point us toward non-traditional models that offer unique advantages for particular research questions.

Darwin's characterization of evolution as "descent with modification" encapsulates two aspects of evolution that can help us assess similarities between species, in particular the matching between a prospective model and its intended target. One is trees that represent the structure of phylogenetic relationships; the other is traits, i.e. each species' uniquely evolved biology and natural history.

\section{Trees}

A species intended to serve as an exemplar for a broader taxon should generally possess symplesiomorphic (ancestral) character states for the traits, mechanisms, or phenomena it is used to study: a species that is too specialized with respect to the traits in question cannot provide a strong basis for inference about its relatives. Assessing a species' potential utility as a model thus requires both an accurate phylogenetic tree and knowledge of how the traits we want to study map onto it [Metscher and Ahl-

Brain Behav Evol 2019;93:82-91 
berg, 1999; Preuss, 2000; Springer and Murphy, 2007; Perlman, 2016]. Such knowledge enables us to gauge at what taxonomic level we might reasonably seek an exemplar, and provides information about which other species such a model can usefully represent.

For instance, much (would-be) translational research focuses on finding and studying homologs of human disease genes in other species. Maxwell et al. [2014] point out that many classes of genes related to human disease are ancient, suggesting that useful, translationally relevant work could be carried out quite effectively in very simple models. On the other hand, some medically important genes are not only vertebrate-specific, but evolve especially rapidly in mammals - for such genes, findings in non-mammalian models may be irrelevant or misleading.

Even if there is a homologous gene, that is merely a plausible starting point: homologs may change in both form and function, and sequence similarity or even homology is no guarantee of shared function [Bolker and Raff, 1996; Arendt and Reznick, 2008; Wagner, 2014; Perlman, 2016]. Networks of gene regulation and functional connectivity also evolve, and recent evidence suggests that evolutionary shifts in the regulatory balance between robustness and efficiency of firing patterns among brain neurons may predispose humans, in particular, to psychopathologies [Abbott, 2019; Pryluk et al., 2019].

Many neuropsychological disorders are characterized by symptoms involving behavioral traits that are either unique to humans, or at least qualitatively different in our species than in others - such as complex language, social interactions, and high-level cognition. The anatomical substratum of these traits may also be human-specific, at levels from gross anatomy to cell type and gene regulation [Preuss, 1995; Matthews et al., 2005; Kaffman and Krystal, 2012; Horwitz et al., 2014; Puzzo et al., 2014; Kelava and Lancaster, 2016; Perlman, 2016; Boldog et al., 2018; Li et al., 2018]. Species disparities that align with human disease risks or states pose critical obstacles to translation: for example, van den Heuvel et al. [2018] have found that the brain structures and connectivity most strongly implicated in schizophrenia are precisely the ones that are absent in our closest relatives. Thus, it may be a better strategy to develop more ways to study schizophrenia in humans than to try to find [or construct: Chen et al., 2017; Katsnelson, 2018] non-human models that adequately represent what may ultimately be a human-specific condition.

However, it is often worth seeking a non-human model: we are not unique in all respects. In order to assess the likelihood of finding useful non-human models, we need to treat the claim that a particular trait is human-specific as a testable hypothesis, and articulate what data or metrics we can use to evaluate it. For instance, while much has been made of the "exceptional" expansion of the neocortex in humans, Finlay and Workman [2013] point out that accounting for developmental timing eliminates the disparity - and there is no reason to seek human-specific explanations for a trait that is not, in fact, exceptional. In cases where human traits of interest involve mechanisms that also operate in other species, those species may offer valuable experimental access: examining conserved mechanisms in exemplary non-human models can shed useful light on our own neurobiology. At the same time, we must avoid conflating a model's value for studying shared mechanisms (construct or structural validity), with its ability to yield results that will translate directly to human clinical applications (predictive validity) [Matthews et al., 2005; Pratt et al., 2012; Blanchard et al., 2013].

The role and value of a given model is determined by both its epistemological and its evolutionary context. Phylogenetic trees provide such context not only by highlighting phenotypic differences and similarities, but also by supporting inferences about the source of similarity. Understanding how evolution has endowed different species with similar traits is relevant both to the initial choice of model for studying a particular question, and then to the interpretation (and potential translation) of results. The two evolutionary routes to similarity are (1) shared ancestry, or homology, and (2) a history of common selection pressures, leading to convergence. That said, the distinction between homology and analogy is not always obvious, nor even binary [A rendt and Reznick, 2008; Wagner, 2014]. Both forms of similarity arise from complex interactions among genetic and environmental factors/influences - and the networks themselves also evolve.

Even though the distinction between homology-based and convergence-based models is not absolute, it offers a useful heuristic for thinking about how we select and employ them. Similarity due to homology and that due to convergence lead to different warrants for extrapolation, and disparate expectations for wider matching. In the case of similarity due to homology, we predict better overall representation of the model species' closer phylogenetic relatives, a better warrant for expecting similarity in additional traits that share ancestry, and stronger inference to closer relatives. In contrast, similarities between model and target that are due to convergence generate different predictions. Here, we expect better representation of other species subject to similar selective pressures, 
Table 1. Different expectations depending on evolutionary source of similarity

\begin{tabular}{ll}
\hline Homology & Convergence \\
\hline $\begin{array}{l}\text { Expect better representation } \\
\text { of closer phylogenetic relatives }\end{array}$ & $\begin{array}{l}\text { Expect better representation of } \\
\text { taxa subject to similar selective } \\
\text { pressures }\end{array}$ \\
\hline $\begin{array}{l}\text { Better warrant for expecting } \\
\text { similarity in additional traits } \\
\text { that share ancestry }\end{array}$ & $\begin{array}{l}\text { Better warrant for expecting } \\
\text { similarity in additional traits } \\
\text { with related adaptive functions }\end{array}$ \\
\hline $\begin{array}{l}\text { Stronger inference to closer } \\
\text { relatives }\end{array}$ & $\begin{array}{l}\text { No inferential premium for } \\
\text { relatives }\end{array}$ \\
\hline
\end{tabular}

and a stronger warrant for expecting similarity in additional traits with related adaptive functions - but no inferential premium for relatives (Table 1).

\section{Traits}

Every species' traits reflect both its lineage and its adaptive history [Day, 1920] - that is, its past selective environment. Natural selection shapes traits that enhance fitness in a given environment; adaptations of particular relevance to neurobiology (and potentially to translational neurobiology research) include functional behaviors [Blanchard et al., 2013; Chalfin et al., 2014], sensory systems [Garner et al., 2017; Peirson et al., 2018], and variations in brain structure associated with diverse habitats and lifestyles [Krubitzer et al., 2011]. The standing biodiversity generated by natural selection offers a vast array of potential models [Krogh, 1929; Pringle, 1966; Krebs, 1975], which are becoming increasingly accessible thanks to development of readily transferable techniques [e.g., Hale, 2019; Juntti, 2019].

Moreover, the "treasure house of nature" [Pringle, $1966]$ is not the only place to look for models: there are plenty of candidates in our own houses. Human-constructed environments have generated their own sets of selection pressures, influencing the evolutionary trajectories of many commensal and/or domesticated species, including most models [Perlman, 2016; Sullivan et al., 2017]. This is, of course, not a coincidence: species that are already familiar, accessible, and tractable are good candidates to become models in the first place. Once they achieve this status, additional (and often extremely stringent) selection pressures related to their new role accelerate their evolution in particular ways and directions. This process has been most extreme - and most thoroughly documented - in rodents. Rodents have a long history of adapting to human cultural niches, across different time scales - from commensalism (thousands of years ago, with the rise of agriculture), to international enthusiasm for fancy mice (about 100 years ago in Britain and North America; much earlier in Asia), to the modern "rodent industrial complex" [Keeler, 1931; Staats, 1966; Logan, 2002; Rader, 2004; Rader, 2007; Francis, 2015; de Jong and Maina, 2010; Green et al., 2018]. Dogs have followed a similar path, though canid disease models are generally bred from lineages with spontaneously occurring mutations, rather than constructed via direct genetic manipulation [Dobson, 2013].

Once a species is selected as a model, its biology can get quite weird: just because mice have evolved to have certain traits in the wild does not mean that laboratory mice necessarily share those traits. Even before humans start deliberately selecting or breeding for particular traits, there is strong natural selection exerted by the novel environment of a laboratory or research colony; as Finlay [2019] puts it, "laboratorization" [Robinson, 1965] involves "selection on little but breeding and surviving in a sterile and changeless environment." The rapid evolutionary divergence of laboratory rodents from the rest of their species is easily explained: laboratory populations are relatively small, highly inbred, and subject to extremely stringent selection (both deliberate, and also because they occupy an environment different in nearly every respect from the habitats that shaped their ancestors' evolution for millions of years). Recent changes in laboratory mice include dramatic shifts in behavior [Blanchard et al., 2013; Chalfin et al., 2014], population genetics [Yang et al., 2011], immune function [Beura et al., 2016; Reese et al., 2016], metabolism, physiology, etc. [Martin et al., 2010; Garner et al., 2017]. Many (though not all) of the recent evolutionary pressures that have shaped rodent models also apply to other model species.

Genetic adaptation to laboratory environments is unlikely to appear in model species that have not been bred in captivity for many generations; but life in the laboratory can still systematically modify phenotypes that are shaped in part by the environment. Environmentally mediated plasticity is fundamental to the development of many aspects of individuals' phenotypes, from metabolism and immunity to neurobiology and behavior [Gilbert and Epel, 2015]. Plastic developmental systems can generate a spectrum of phenotypes "tuned" to a range of external conditions including abiotic factors such as light and temperature, and biotic ones such as predation threat 
or social context. However, cues that help shape phenotypic development in a species' normal environment may be altered or even absent in the laboratory. Because animals reared under laboratory conditions are partially shaped by that highly modified environment, their phenotypes may differ from the normal "wild-type" for the species. If we have chosen a model based on the natural occurrence of a neurobiological or behavioral trait that plausibly represents a phenotype we hope to understand (either in general or in humans), we must confirm that the phenotype is not significantly altered in laboratoryreared individuals.

Many neurobiological traits, including behavior and brain development, are known to be sensitive to environmental parameters that may be poorly controlled, incompletely documented, or outside the species' normal range in laboratory settings [Crabbe et al., 1999; Martin et al., 2010; Garner et al., 2017]. For instance, standardized rodent housing drastically limits both the physical and the social complexity of the animal's environment, with wellestablished effects on brain development and behavior [Mo et al., 2016; Bayne, 2018]. Another example is exposure (or lack of exposure) to other species, particularly microbes [Beura et al., 2016; Reese et al., 2016]. Increasing evidence of strong links between the immune system, the microbiome, and the nervous system [Collins et al., 2012; Cryan and Dinan, 2012; Dinan et al., 2014; Valles-Colomer et al., 2019] should raise red flags about relying on animals raised in clean laboratory conditions to study neuroscience and biomedical questions for which this linkage may be relevant. Unrealistically simplified models such as pathogen-free mice are useful for alerting us to the importance of environmental cues, but not as a means to study phenotypes that those cues normally help to shape. Using laboratory-reared animal models to represent real-world biology requires that we treat environmental cues (or their absence) as important variables, not merely incidental byproducts of carefully simplified and standardized husbandry protocols [Richter et al., 2011; Bolker, 2014; Toth, 2015; Mo et al., 2016; Franklin and Ericsson, 2017; Bayne, 2018].

\section{Natural History}

Despite their common characterization as tools or "media" [Keeler, 1931], model animals remain biological organisms, not furry test tubes [Toth, 2015; Mo et al., 2016; Garner et al., 2017]. Every species has its own particular natural history, and concomitant traits that may be highly relevant to the species' potential function as a model [e.g. Abbott et al., 2003; Perlman, 2016]. Emphasizing the biological nature of model organisms has important implications for modeling practices.

First, recognizing interspecific differences that have evolved as adaptations to different habitats and lifestyles can help us avoid errors based on assumed (but untested) similarities between model and target. Uncritical assumptions about what matters to another species can lead to experimental designs, particularly behavioral assays, that are deeply flawed - and very unlikely to yield translatable results [Matthews et al., 2005; Pratt et al., 2012; Chalfin et al., 2014; Chadman et al., 2009]. Visual information that is easily perceived by a human investigator may be obscure to a mouse [Peirson et al., 2018]; conversely, stimuli that do not bother us can stress rodents [Garner et al., 2017], and a mouse that exhibited the behavioral traits of a healthy person would be a very abnormal mouse (and vice versa).

Second, we must account for animals' species-specific biology when we bring them into the laboratory, both for their general welfare and also to support expression of their normal phenotypes (unless we are deliberately manipulating the environment to induce stress, disease, or some other phenomenon we want to study). Essential to that biology is their evolutionary history - which is, of course, different from our own [Perlman, 2016]. The rodent models that dominate biomedical research have undergone roughly 90 million years of independent evolution since our last common ancestor, while chimpanzee and human lineages diverged about 7 million years ago [Kumar et al., 2017]. That long separate history has led to profound differences; yet researchers tend to stress similarities, since those are the justification for using other species as models for humans.

This bias may be exacerbated by a particularly human trait, namely a tendency to attribute human traits to members of other species. While often highly effective in literature [Kipling, 1898; Potter, 1903], anthropomorphism is problematic in science. Beyond the immediate challenge of interpreting other animals' behavior [Povinelli, 2004], we may fail to consider the environmental sensitivities of other species, and the conditions to which they are adapted [Garner et al., 2017]: what do they perceive as a comfortable temperature [Gordon, 2017], or an annoying background noise? What housing conditions cause stress: solitude, or crowding? What qualifies as environmental enrichment [Mo et al., 2016; Bayne, 2018]? Human answers to such questions may not match the responses another species would provide; it is up to re-
86

Brain Behav Evol 2019;93:82-91 DOI: $10.1159 / 000500317$
Bolker 
searchers to devise ways to ascertain what their non-human subjects' answers would be, and design husbandry and experimental protocols accordingly.

\section{Discussion}

As Krogh pointed out, there are a lot of potentially useful models out there, and knowing something about the natural history and unique biology of a wide variety of species can help us find the ones that are "best suited for particular problems" [Krogh, 1929; Krebs, 1975]. Nevertheless, finding good models for translational neuroscience remains a challenge. Some of the things we want to study are unique to humans [Matthews et al., 2005; Kaffman and Krystal, 2012; Horwitz et al., 2014; Puzzo et al., 2014; Kelava and Lancaster, 2016; Li et al., 2018; Boldog et al., 2018; Nesse, 2019]: for example, schizophrenia probably does not exist in a comparable form in any other species that might serve as a surrogate for human patients [van den Heuvel et al., 2018]. Moreover, critical gaps in our knowledge of human biology - in particular, our limited understanding of the biology of neuropsychiatric disorders - makes selecting non-human models for translational research especially difficult, because we are aiming at a target that is not yet clear.

Focusing on research goals that are clinically relevant to humans is essential to enhance the translational value of animal models [Matthews et al., 2005; Insel, 2007; Jucker, 2010; Nestler and Hyman, 2010; Pratt et al., 2012; Hyman, 2012; Blanchard et al., 2013; Garner, 2014; Horwitz et al., 2014; McGonigle, 2014; O'Tuathaigh and Waddington, 2015; Papassotiropoulos and de Quervain, 2015; Garner et al., 2017]. We must articulate exactly how traits and outcomes we measure in models relate to the human phenomena we intend them to represent, and resist the temptation to allow nominally "disorder-like" phenotypes in models to supplant the actual research targets [van der Staay et al., 2009; Blanchard et al., 2013; Horwitz et al., 2014; Garner, 2014; Bolker, 2017]. Garner [2014] offers a particularly damning assessment of "meaningless but easily automated measures" used for behavioral phenotyping in putative models of neuropsychiatric disorders. Continuing to rely on tests optimized for efficiency rather than information, in models chosen for their familiarity rather than their ability to represent the target of interest, all but guarantees continued translational failure [Bolker, 2017].

One problem is that standard behavioral assessments may depend on aspects of the model's biology that have nothing to do with what we are trying to study, for example the Morris Water Maze used to evaluate memory function in rodents: "The single biggest predictor of performance in the [Morris Water Maze] is the degree of retinal atrophy of the mouse, not memory [Brown and Wong, 2007]. That is, the MWM could just as well be interpreted as a measure of blindness not memory" [Garner, 2014]. Another issue is that even when behavioral tests do assess the trait they are meant to measure, the behavioral phenotype being scored in the model may have little relationship to the human condition we are trying to study: "At the most extreme, researchers with no human clinical knowledge will latch onto completely superficial behavioral similarities, label them '-like,' and actually use behaviors in mice that would indicate differential diagnoses in humans" [Garner, 2014]. Such errors are easier to make when - as is often the case - diagnoses are based on clinical criteria that cannot be evaluated in other species.

Moreover, even in humans, clinical diagnostic criteria are not necessarily closely tied to the underlying biology [Nestler and Hyman, 2010; Hyman, 2012; Nesse, 2019]. Without at least some knowledge (or at least hypotheses) about the biological basis of the human disorder, it is impossible to tell whether essential disease mechanisms are present in other species. If key aspects of the etiology and mechanisms of neuropsychiatric disorders are rooted in regulatory patterns unique to our own lineage, there may be no other species capable of representing them effectively or serving as a surrogate model. In such cases we need to shift from searching for adequate non-human models, and instead invest in developing ethical, feasible ways of studying humans directly: sometimes it may be impossible to learn from another species what we need to know about ourselves.

However, it is often possible (or at least worth trying), and there are ongoing efforts to refine and strengthen interspecific comparisons, articulate disease criteria that can be applied to models as well as to patients, and identify endophenotypes that can be assayed in both human and non-human models [Chadman et al., 2009; Insel et al., 2010; Nestler and Hyman, 2010; Cuthbert, 2014]. One way forward is the development of new technologies for studying humans directly, such as real-time imaging of living patients, techniques for analyzing human tissues both in real time and postmortem [Li et al., 2018; Pryluk et al., 2019], and increasingly complex in vitro models of human tissues [Kelava and Lancaster, 2016]. In the short term, we can use these systems to complement wholeorganism models from other species, and ground-truth 
Table 2. Questions that should be asked

\begin{tabular}{ll}
\hline Aspect of evolution & Key questions about a species' potential use as a model \\
\hline Trees (phylogeny) & What is its phylogenetic and taxonomic position? \\
& What are its closest relatives? \\
& How have domestic or laboratory strains evolved since diverging from ancestral lineages or stocks? \\
& How closely related is it to humans; when did our lineages diverge? \\
& What was our last common ancestor like? \\
\hline Traits (characters/attributes) & $\begin{array}{l}\text { At what phylogenetic level do traits of interest appear? } \\
\text { Do similar traits result from homology or from convergence? }\end{array}$ \\
& What traits are likely to have arisen as adaptations to a specific niche? \\
& What are the species' primary sensory modalities, and their capacities? \\
& What aspects of the phenotype demonstrate plasticity? \\
& Does the trait of interest occur naturally or is it experimentally induced? If induced, are there side \\
effects or disparities that should be considered?
\end{tabular}

the latter by comparison with human models at various scales. In the long term, human and human-based systems may be able to replace non-human models for much basic biomedical research, which should dramatically narrow the translational gap.

Meanwhile, a conscious evolutionary framework (filled in with knowledge from zoology and comparative neurobiology) can inform choices about which models are most likely to yield translatable knowledge about neurobiology. Because there is no single right answer or "best" model, we need to pursue several parallel approaches: continue to invest in "core" species, develop a greater diversity of models [Brenowitz and Zakon, 2015; Yartsev, 2017], and leverage new tools that provide access to non-traditional model species that offer unique advantages for specific kinds of studies [Hale, 2019; Juntti, 2019]. Evolutionary thinking can guide all three strategies.

Seeing where traits arise in phylogeny can help us figure out how deep in the tree we can reasonably go in search of models to analyze disease mechanisms: if a gene or process associated with a human disease occurs in a simpler, more tractable model, that model can be a powerful research tool [Maxwell et al., 2014]. If the phenomenon only occurs in humans, we are unlikely to find useful model organisms elsewhere in the tree; instead, we must focus on alternative approaches that include essential human elements, whether in vitro or in vivo. There is now a rapidly expanding array of hybrid models such as mice and monkeys that incorporate human genes, cells, or microbiota [e.g., Piotrowska, 2013; Ehret et al., 2017; Okano and Kishi, 2018]. But all complex biological relationships - such as host-microbe assemblages, or the anatomical and functional connectivity within the central nervous system - have a unique evolutionary history, and attempts to represent those relationships using other combinations of species (or their cells) introduce serious biological and epistemological uncertainties.

Paying attention to evolution can help us recapture the historical view of diversity as a resource for both basic and translational research, rather than an obstacle [Logan, 2002; Bolker and Brauckmann, 2015]. Researchers in search of animal models well-suited to particular problems can still benefit from Krogh's 1929 advice to "apply to the zoologists to find them," rather than default to whatever species currently dominates the field [Bolker, 2017]. Each species' particular constellation of traits helps determine how, and for what, it might work as a model - and there are several distinct epistemological roles a model can play [Green et al., 2018].

The first is that the model can match the target with respect to the trait in question: its representational function can be based on direct, relevant similarities. The degree and nature of matching that is required depends on what type of validity one hopes to claim for results in the model (compared to the target, e.g., a human patient): in 
translational research, the quest is usually for either construct validity (same mechanism) or predictive validity (response in model reliably predicts that in human). Traits that are unrelated to the phenotype in question do not need to match at all: for example, the color of a mouse's fur needn't match the pelage of the human patient for whom it serves as a preclinical proxy.

Second, a model can offer experimental access to the trait of interest - a venue where it is "most convenient to study." Such access may be fortuitous (as in the case of the tortoises cited by Krogh, whose anteriorly branching bronchi make them convenient for respiratory physiology), or it may take the form of unusually pronounced adaptations or specializations, such as owls' visual processing or cichlids' extraordinary behavioral and craniofacial diversity [Mysore and Knudsen, 2013; Powder and Albertson, 2016; Schryver and Mysore, 2019].

Finally, it may contrast with the target: the model might be good at something the target is bad at, or resistant to a problem to which the target is susceptible (Green et al. [2018] term these "negative models," and discuss several examples). For instance, compared to humans, mice are dramatically more resistant to bacterial endotoxins that cause sepsis: given their lifestyle, they have to be [Mestas and Hughes, 2004; Webb et al., 2015]. This evolved disparity limits their value as surrogate models for representing sepsis in humans [Seok et al., 2013; Fink, 2014; Webb et al., 2015] - but studying the biological basis of murine resistance to sepsis, or mole rats' resistance to cancer [Edrey et al., 2011], could help us figure out more effective ways to prevent or treat these problems in our own species.
Evolution offers both a rich source of possible models, and guidance for choosing the best ones for a given purpose. The greatest benefit of considering model choice from an evolutionary angle is not to see new answers ("What species might be a good model for studying x?"), but to recognize key questions we should be asking as we evaluate potential (or current) models (Table 2). An evolutionary perspective lets us look both backward and forward in the quest for useful models for neuroscience. Looking back at each species' unique evolutionary history and phylogeny provides critical information about relationships, the distribution of traits, and the origin of similarities. Looking forward, we can use these insights to refine inferences based on model species we already use, as well as to guide the search for new ones that will expand our knowledge of neurobiology both in general, and in ourselves.

\section{Acknowledgments}

The author thanks Dr. Georg Striedter and Dr. Todd Preuss for organizing the workshop and inviting her to participate.

\section{Statement of Ethics}

The author has no ethical conflicts to disclose.

\section{Disclosure Statement}

The author declares no conflicts of interest.

\section{References}

Abbott A. Pioneering brain study reveals 'software' differences between humans and monkeys. Nature. 2019;565(7740):410-1.

Abbott DH, Barnett DK, Colman RJ, Yamamoto ME, Schultz-Darken NJ. Aspects of common marmoset basic biology and life history important for biomedical research. Comp Med. 2003 Aug;53(4):339-50.

Amundson R. The changing role of the embryo in evolutionary thought: Roots of Evo-Devo. Cambridge: Cambridge Univ Press; 2005. https://doi.org/10.1017/CBO9781139164856.

Arendt J, Reznick D. Convergence and parallelism reconsidered: what have we learned about the genetics of adaptation? Trends Ecol Evol. 2008 Jan;23(1):26-32.

Bayne K. Environmental enrichment and mouse models: current perspectives. Animal Model Exp Med. 2018 Jul;1(2):82-90.
Beura LK, Hamilton SE, Bi K, Schenkel JM, Odumade OA, Casey KA, et al. Normalizing the environment recapitulates adult human immune traits in laboratory mice. Nature. 2016 Apr;532(7600):512-6.

Blanchard DC, Summers CH, Blanchard RJ. The role of behavior in translational models for psychopathology: functionality and dysfunctional behaviors. Neurosci Biobehav Rev. 2013 Sep;37(8):1567-77.

Boldog E, Bakken TE, Hodge RD, Novotny M, Aevermann BD, Baka J, et al. Transcriptomic and morphophysiological evidence for a specialized human cortical GABAergic cell type. Nat Neurosci. 2018 Sep;21(9):1185-95.

Bolker JA. From genotype to phenotype: looking into the black box. In: Kumar S, Bentley PJ, editors. On growth, form and computers. Oxford: Elsevier; 2003. pp. 82-91.
Bolker JA. Exemplary and surrogate models: two modes of representation in biology. Perspect Biol Med. 2009;52(4):485-99.

Bolker JA. Models in context: biological and epistemological niches. In: Barker G, Desjardins E, Pearce T, editors. Entangled life: organism and environment in the biological and social sciences. Dordrecht: Springer Netherlands; 2014. pp. 153-66.

Bolker JA. Animal models in translational research: Rosetta Stone or stumbling block? BioEssays. 2017 Dec;39(12): 1700089.

Bolker JA, Brauckmann S. From experimental zoology to big data: observation and integration in the study of animal development. J Exp Zool A Ecol Genet Physiol. 2015 Jun;323(5):277-91.

Bolker JA, Raff RA. Developmental genetics and traditional homology. BioEssays. 1996 Jun; 18(6):489-94.
Selection of Models for Translational Research
Brain Behav Evol 2019;93:82-91 DOI: $10.1159 / 000500317$ 
Brenowitz EA, Zakon HH. Emerging from the bottleneck: benefits of the comparative approach to modern neuroscience. Trends Neurosci. 2015 May;38(5):273-8.

Brown RE, Wong AA. The influence of visual ability on learning and memory performance in 13 strains of mice. Learn Mem. 2007 Mar; 14(3):134-44

Chadman KK, Yang M, Crawley JN. Criteria for validating mouse models of psychiatric diseases. Am J Med Genet B Neuropsychiatr Genet. 2009 Jan;150B(1):1-11.

Chalfin L, Dayan M, Levy DR, Austad SN, Miller RA, Iraqi FA, et al. Mapping ecologically relevant social behaviours by gene knockout in wild mice. Nat Commun. 2014 Aug;5(1): 4569.

Chen Y, Yu J, Niu Y, Qin D, Liu H, Li G, et al. Modeling Rett Syndrome using TALEN-edited MECP2 mutant Cynomolgus monkeys. Cell. 2017 May;169(5):945-955.e10.

Collins SM, Surette M, Bercik P. The interplay between the intestinal microbiota and the brain. Nat Rev Microbiol. 2012 Nov; 10(11):735-42.

Crabbe JC, Wahlsten D, Dudek BC. Genetics of mouse behavior: interactions with laboratory environment. Science. 1999 Jun;284(5420): $1670-2$.

Cryan JF, Dinan TG. Mind-altering microorganisms: the impact of the gut microbiota on brain and behaviour. Nat Rev Neurosci. 2012 Oct;13(10):701-12.

Cuthbert BN. Translating intermediate phenotypes to psychopathology: the NIMH Research Domain Criteria. Psychophysiology. 2014 Dec;51(12):1205-6.

Day C. This simian world. New York: Alfred A. Knopf; 1920.

de Jong M, Maina T. Of mice and humans: are they the same? - Implications in cancer translational research. J Nucl Med. 2010 Apr;51(4): 501-4.

Dinan TG, Borre YE, Cryan JF. Genomics of schizophrenia: time to consider the gut microbiome? Mol Psychiatry. 2014 Dec;19(12): $1252-7$.

Dobson JM. Breed-predispositions to cancer in pedigree dogs. ISRN Vet Sci. 2013 Jan;2013: 941275.

Edrey YH, Hanes M, Pinto M, Mele J, Buffenstein R. Successful aging and sustained good health in the naked mole rat: a long-lived mammalian model for biogerontology and biomedical research. ILAR J. 2011;52(1):41-53.

Ehret T, Torelli F, Klotz C, Pedersen AB, Seeber F. Translational rodent models for research on parasitic protozoa - a review of confounders and possibilities. Front Cell Infect Microbiol. 2017 Jun;7:238.

Fink MP. Animal models of sepsis. Virulence. 2014 Jan;5(1):143-53.

Finlay BL. Generic Homo sapiens and unique Mus musculus: establishing the typicality of the modeled and the model species. Brain Behav Evol. 2019. DOI: https://doi.org/ $10.1159 / 000500111$.
Finlay BL, Workman AD. Human exceptionalism. Trends Cogn Sci. 2013 May;17(5):199201.

Francis RC. Domesticated: evolution in a manmade world. New York: W.W. Norton and Company Inc.; 2015.

Franklin CL, Ericsson AC. Microbiota and reproducibility of rodent models. Lab Anim (NY). 2017 Mar;46(4):114-22.

Garner JP. The significance of meaning: why do over $90 \%$ of behavioral neuroscience results fail to translate to humans, and what can we do to fix it? ILAR J. 2014;55(3):438-56.

Garner JP, Gaskill BN, Weber EM, Ahloy-Dallaire J, Pritchett-Corning KR. Introducing Therioepistemology: the study of how knowledge is gained from animal research. Lab Anim (NY). 2017 Mar;46(4):103-13.

Gilbert SF, Epel D. Ecological developmental biology: the environmental regulatiom of development, health, and evolution. Sunderland (MA): Sinauer Associates Inc.; 2015

Gordon CJ. The mouse thermoregulatory system: its impact on translating biomedical data to humans. Physiol Behav. 2017 Oct;179:55-66.

Green S, Dietrich MR, Leonelli S, Ankeny RA. 'Extreme' organisms and the problem of generalization: interpreting the Krogh principle. Hist Philos Life Sci. 2018 Oct;40(4):65.

Hale M. Toward diversification of species models in neuroscience. Brain Behav Evol. 2019. DOI: https://doi.org/10.1159/000500499.

Horwitz RI, Abell JE, Christian JB, Wivel AE. Right answers, wrong questions in clinical research. Sci Transl Med. 2014 Jan;6(221): 221 fs5.

Hyman SE. Revolution stalled. Sci Transl Med. 2012 Oct;4(155): $155 \mathrm{~cm} 11$.

Insel TR. From animal models to model animals. Biol Psychiatry. 2007 Dec;62(12):1337-9.

Insel T, Cuthbert B, Garvey M, Heinssen R, Pine DS, Quinn K, et al. Research domain criteria (RDoC): toward a new classification framework for research on mental disorders. Am J Psychiatry. 2010 Jul;167(7):748-51.

Jucker M. The benefits and limitations of animal models for translational research in neurodegenerative diseases. Nat Med. 2010 Nov; 16(11):1210-4.

Juntti SA. The future of gene-guided neuroscience research in non-traditional model organisms. Brain Behav Evol. 2019. DOI: https://doi.org/10.1159/000500072.

Kaffman A, Krystal JH. New frontiers in animal research of psychiatric illness. Methods Mol Biol. 2012;829:3-30.

Katsnelson A. Modeling autism. Lab Anim (NY), 2018 Jan; 47(2):41-4.

Keeler CE. The laboratory mouse: its origin, heredity, and culture. Cambridge (MA): Harvard University Press; 1931. https://doi. org/10.4159/harvard.9780674336988.

Kelava I, Lancaster MA. Stem cell models of human brain development. Cell Stem Cell. 2016 Jun;18(6):736-48.

Kipling R. The Maltese cat. In: The day's work. London: Macmillan; 1898.
Krebs HA. The August Krogh Principle: "For many problems there is an animal on which it can be most conveniently studied". J Exp Zool. 1975 Oct;194(1):221-6.

Krogh A. Progress in physiology. Science. 1929 Aug;70(1809):200-4

Krubitzer L, Campi KL, Cooke DF. All rodents are not the same: a modern synthesis of cortical organization. Brain Behav Evol. 2011;78(1): 51-93.

Kumar S, Stecher G, Suleski M, Hedges SB. TimeTree: a resource for timelines, timetrees, and divergence times. Mol Biol Evol. 2017 Jul; 34(7):1812-9.

Li M, Santpere G, Imamura Kawasawa Y, Evgrafov OV, Gulden FO, Pochareddy S, et al.; Brainspan Consortium; PsychENCODE Consortium; PsychENCODE Developmental Subgroup. Integrative functional genomic analysis of human brain development and neuropsychiatric risks. Science. 2018 Dec; 362(6420):eaat7615.

Logan CA. Before there were standards: the role of test animals in the production of empirical generality in physiology. J Hist Biol. 2002; 35(2):329-63.

Martin B, Ji S, Maudsley S, Mattson MP. "Control" laboratory rodents are metabolically morbid: why it matters. Proc Natl Acad Sci USA. 2010 Apr;107(14):6127-33.

Matthews K, Christmas D, Swan J, Sorrell E. Animal models of depression: navigating through the clinical fog. Neurosci Biobehav Rev. 2005; 29(4-5):503-13.

Maxwell EK, Schnitzler CE, Havlak P, Putnam $\mathrm{NH}$, Nguyen AD, Moreland RT, et al. Evolutionary profiling reveals the heterogeneous origins of classes of human disease genes: implications for modeling disease genetics in animals. BMC Evol Biol. 2014 Oct;14(1):21229.

McGonigle P. Animal models of CNS disorders. Biochem Pharmacol. 2014 Jan;87(1):140-9.

Mestas J, Hughes CC. Of mice and not men: differences between mouse and human immunology. J Immunol. 2004 Mar;172(5):2731-8.

Metscher BD, Ahlberg PE. Zebrafish in context: uses of a laboratory model in comparative studies. Dev Biol. 1999 Jun;210(1):1-14.

Mo C, Renoir T, Hannan AJ. What's wrong with my mouse cage? Methodological considerations for modeling lifestyle factors and geneenvironment interactions in mice. J Neurosci Methods. 2016 May;265:99-108.

Mysore SP, Knudsen EI. A shared inhibitory circuit for both exogenous and endogenous control of stimulus selection. Nat Neurosci. 2013 Apr;16(4):473-8.

Nesse RM. Good reasons for bad feelings: insights from the frontier of evolutionary psychiatry. 1st ed. New York: Dutton; 2019.

Nesse RM, Bergstrom CT, Ellison PT, Flier JS, Gluckman P, Govindaraju DR, et al. Evolution in health and medicine Sackler colloquium: making evolutionary biology a basic science for medicine. Proc Natl Acad Sci USA. 2010 Jan;107 Suppl 1:1800-7.
90

Brain Behav Evol 2019;93:82-91

DOI: $10.1159 / 000500317$
Bolker 
Nestler EJ, Hyman SE. Animal models of neuropsychiatric disorders. Nat Neurosci. 2010 Oct;13(10):1161-9.

O’Tuathaigh CM, Waddington JL. Closing the translational gap between mutant mouse models and the clinical reality of psychotic illness. Neurosci Biobehav Rev. 2015 Nov;58: 19-35.

Okano H, Kishi N. Investigation of brain science and neurological/psychiatric disorders using genetically modified non-human primates. Curr Opin Neurobiol. 2018 Jun;50:1-6.

Papassotiropoulos A, de Quervain DJ. Failed drug discovery in psychiatry: time for human genome-guided solutions. Trends Cogn Sci. 2015 Apr;19(4):183-7.

Peirson SN, Brown LA, Pothecary CA, Benson LA, Fisk AS. Light and the laboratory mouse. J Neurosci Methods. 2018 Apr;300:26-36.

Perlman RL. Mouse models of human disease: an evolutionary perspective. Evol Med Public Health. 2016 May;2016(1):170-6.

Piotrowska M. From humanized mice to human disease: guiding extrapolation from model to target. Biol Philos. 2013;28(3):439-55.

Potter B. The tailor of Gloucester. London: Frederick Warne and Company; 1903.

Povinelli DJ. Behind the ape's appearance: escaping anthropocentrism in the study of other minds. Daedalus. 2004;133(1):29-41.

Powder KE, Albertson RC. Cichlid fishes as a model to understand normal and clinical craniofacial variation. Dev Biol. 2016 Jul;415(2): $338-46$.

Pratt J, Winchester C, Dawson N, Morris B. Advancing schizophrenia drug discovery: optimizing rodent models to bridge the translational gap. Nat Rev Drug Discov. 2012 Jun; 11(7):560-79.

Preuss TM. Do rats have prefrontal cortex? The rose-woolsey-akert program reconsidered. J Cogn Neurosci. 1995;7(1):1-24.

Preuss TM. Taking the measure of diversity: comparative alternatives to the model-animal paradigm in cortical neuroscience. Brain Behav Evol. 2000 Jun;55(6):287-99.

Pringle JW. The treasure-house of nature. Adv Sci. 1966 Oct;23(112):297-304.
Pryluk R, Kfir Y, Gelbard-Sagiv H, Fried I, Paz R. A tradeoff in the neural code across regions and species. Cell. 2019 Jan;176(3):597-609. e18.

Puzzo D, Lee L, Palmeri A, Calabrese G, Arancio O. Behavioral assays with mouse models of Alzheimer's disease: practical considerations and guidelines. Biochem Pharmacol. 2014 Apr;88(4):450-67.

Rader KA. Making mice: standardizing animals for American biomedical research, 19001955. Princeton (NJ): Princeton University Press; 2004.

Rader K. The metaphor of domestication in genetics. In: Cassidy R, Mullin M, editors. Where the wild things are now: domestication reconsidered. New York: Berg; 2007.

Reese TA, Bi K, Kambal A, Filali-Mouhim A, Beura LK, Bürger MC, et al. Sequential infection with common pathogens promotes humanlike immune gene expression and altered vaccine response. Cell Host Microbe. 2016 May; 19(5):713-9.

Richter SH, Garner JP, Zipser B, Lewejohann L, Sachser N, Touma C, et al. Effect of population heterogenization on the reproducibility of mouse behavior: a multi-laboratory study. PLoS One. 2011 Jan;6(1):e16461.

Robinson R. Genetics of the Norway rat. Oxford: Pergamon Press; 1965.

Schryver HM, Mysore SP. Spatial dependence of stimulus competition in the avian nucleus isthmi pars magnocellularis. Brain Behav Evol. 2019. DOI: https://doi.org/10.1159/ 000500192.

Seok J, Warren HS, Cuenca AG, Mindrinos MN Baker HV, Xu W, et al.; Inflammation and Host Response to Injury, Large Scale Collaborative Research Program. Genomic responses in mouse models poorly mimic human inflammatory diseases. Proc Natl Acad Sci USA. 2013 Feb;110(9):3507-12.

Springer MS, Murphy WJ. Mammalian evolution and biomedicine: new views from phylogeny. Biol Rev Camb Philos Soc. 2007 Aug;82(3): $375-92$.
Staats J. The laboratory mouse. In: Green EL, editor. Biology of the laboratory mouse. 2nd ed. New York: McGraw-Hill Book Company; 1966. pp. 1-9.

Steel D. Across the boundaries: extrapolation in biology and social science. Oxford: Oxford University Press; 2008.

Striedter GF. Variation across species and levels: implications for model species research. Brain Behav Evol. 2019. DOI: https://doi.org/ 10.1159/000499664.

Sullivan AP, Bird DW, Perry GH. Human behaviour as a long-term ecological driver of nonhuman evolution. Nat Ecol Evol. 2017;1:0065.

Toth LA. The influence of the cage environment on rodent physiology and behavior: implications for reproducibility of pre-clinical rodent research. Exp Neurol. 2015 Aug;270:72-7.

Valles-Colomer M, Falony G, Darzi Y, Tigchelaar $\mathrm{EF}$, Wang J, Tito RY, et al. The neuroactive potential of the human gut microbiota in quality of life and depression. Nat Microbiol. 2019 Apr;4(4):623-32.

van den Heuvel MP, Scholtens LH, de Lange SC, Pijnenburg R, Wiepke C, van Haren NE, et al. Evolutionarily developed connections compromised in schizophrenia. bioRxiv. 2018; https://doi.org/10.1101/387506.

van der Staay FJ, Arndt SS, Nordquist RE. Evaluation of animal models of neurobehavioral disorders. Behav Brain Funct. 2009 Feb;5(1): 11.

Wagner GP. Homology, genes, and evolutionary innovation. Princeton (NJ): Princeton University Press; 2014.

Webb AE, Gerek ZN, Morgan CC, Walsh TA, Loscher CE, Edwards SV, et al. Adaptive evolution as a predictor of species-specific innate immune response. Mol Biol Evol. 2015 Jul; 32(7):1717-29.

Yang H, Wang JR, Didion JP, Buus RJ, Bell TA, Welsh CE, et al. Subspecific origin and haplotype diversity in the laboratory mouse. Nat Genet. 2011 May;43(7):648-55.

Yartsev MM. The emperor's new wardrobe: rebalancing diversity of animal models in neuroscience research. Science. 2017 Oct;358(6362): 466-9.
Selection of Models for Translational

Research
Brain Behav Evol 2019;93:82-91

DOI: $10.1159 / 000500317$ 